Gut and Liver, Vol. 13, No. 1, January 2019, pp. 7-10

\title{
Tips for Responding to Reviewers' Comments-from an Editor's or Reviewer's Points of View
}

\author{
Grace Lai-Hung Wong ${ }^{1,2,3}$ \\ ${ }^{1}$ Institute of Digestive Disease, ${ }^{2}$ Department of Medicine and Therapeutics, and ${ }^{3}$ State Key Laboratory of Digestive Disease, The Chinese \\ University of Hong Kong, Hong Kong SAR, China
}

Peer review is the indispensable part of publishing a scientific paper, in particulars in high-impact journals. This is to ensure the quality, originality and accuracy of the work submitted to the journals. ${ }^{1}$ The next immediate step after peer review, if the authors are lucky enough, is to revise the manuscript according to editors' and reviewers' comments. ${ }^{2}$ This is an important step as the valuable and insightful comments from the editors and reviewers, who are often the experts in the field, would improve the manuscript substantially. These comments are vital means of communication between the authors and reviewers. Most journals would invite at least two to three reviewers, and occasionally even up to six reviewers. However, the brutal reality is that the more reviewers being invited, the higher the likelihood of getting some harsh, conflicting comments on the manuscript.

Even majority of the revised manuscripts will get accepted by the journals, it is not uncommon to encounter rejection after first, second, or rarely third round of revision. ${ }^{3}$ In order to minimize the chance of this "mishap"-rejection after revision, the authors should try to address the comments as complete as possible. There is never any hard-and-fast rules leading to a secured, guaranteed acceptance after revision. The following is the discussion on some general principles and sharing from personal experience, be it good or bad one, in responding reviewers' comments.

\section{HOW LIKELY IS MY PAPER BEING ACCEPTED AFTER REVISION?}

The first sign of the probability of being accepted (and the reverse, rejected) after revision is the categories of decision"Accept," “Accept after Revision/Minor Revision," "Reject with Hope/Major revision," or "Reject.” The most challenging category is likely the "Reject with Hope/Major revision" (Table 1).
These sentences allow rooms for the editors and reviewers to reserve the right of rejecting the papers even after revision.

\section{HOW TO START ADDRESSING THE REVIEWERS-DIGEST THEIR COMMENTS}

The key reason of rejection after revision is the major comments have not been adequately addressed. ${ }^{3}$ Hence digesting the reviewers' comments, preferably over a few days would be helpful. ${ }^{3}$ One approach suggested for digesting the reviewers' comments involves reading the reviews once, putting it aside for a couple of days, followed by reading the reviews again, and finally discussing the reviews with the co-authors to create the plan of response.

It is a must to address all the comments; yet addressing does not always mean changing the manuscript. ${ }^{4}$ The key authors (most often first, second and corresponding authors) should discuss and decide what to change, and what to defend. Changing according to the comments is often the easiest route, as this demonstrates openness to suggestions. Nonetheless, disagreement is also fine, or it is indeed part of the revision process. Just that it would be important that the authors can back it up and support with data and facts. Occasionally the reviewers' comments may be partial. It would be nice and decent to have a complete, solid and polite rebuttal to the editor. Always write in such a manner that the response can be forwarded to the reviewers, which often makes the life of editors easier by copying and pasting the responses in their decision e-mails.

\section{MATERIALS TO BE PREPARED FOR RESUBMISSION}

\section{Cover letter/Letter to the editor}

Letter to the editor summarizing the changes and, if neces-

Correspondence to: Grace Lai-Hung Wong

Department of Medicine and Therapeutics, The Chinese University of Hong Kong, 9/F, Lui Che Woo Clinical Sciences Building, Prince of Wales Hospital, Shatin, Hong Kong

Tel: +852-3505-3996, Fax: +852-2637-3852, E-mail: wonglaihung@cuhk.edu.hk

pISSN 1976-2283 eISSN 2005-1212 https://doi.org/10.5009/gnl18361

() This is an Open Access article distributed under the terms of the Creative Commons Attribution Non-Commercial License (http://creativecommons.org/licenses/by-nc/4.0) which permits unrestricted non-commercial use, distribution, and reproduction in any medium, provided the original work is properly cited. 
Table 1. Common Sentences Included in the Decision E-mails from Journal Editors

\begin{tabular}{|c|c|}
\hline Decision & E-mail content \\
\hline Major revision & $\begin{array}{l}\text { Unfortunately, we are unable to accept your paper for publication. However, if you believe you can address all of the } \\
\text { reviewers' comments, we would be pleased to see a revised manuscript which will be subject to further peer-review, and } \\
\text { with no guarantee of ultimate acceptance. }\end{array}$ \\
\hline Rejection with hope & $\begin{array}{l}\text { Your paper is not accepted for publication in its current form. The editors and reviewers found it very interesting, } \\
\text { but there were substantial limitations raised. If you can fully address these issues and concerns, we are interested in } \\
\text { reviewing a revised version of the manuscript. We cannot offer any assurance that it will be accepted after revision and } \\
\text { resubmission. }\end{array}$ \\
\hline Reject after revision & $\begin{array}{l}\text { We have now received all of the peer reviewers' reports for your manuscript. While we greatly appreciate the efforts that } \\
\text { have gone into revising the manuscript, the reviewers unfortunately still feel that the manuscript does not meet the } \\
\text { requirements of Original Research for the Journal. Therefore, on this occasion, we have decided not to publish your } \\
\text { manuscript. }\end{array}$ \\
\hline & $\begin{array}{l}\text { Although the authors tried their best they have not been able, unfortunately, to address the raised issues because of major } \\
\text { design flaws. The reviewer is not convinced by the conclusions drawn by the authors because... }\end{array}$ \\
\hline
\end{tabular}

Table 2. Good and Bad Sentence Starters for Responding Reviewers' Comments

\begin{tabular}{|c|c|}
\hline Good example & Bad example \\
\hline We would like to thank the reviewer for the interest on this topic... & I do not think the reviewers understand my point... \\
\hline The Reviewer has correctly pointed out that... & $\begin{array}{l}\text { It would not necessary to change according to the reviewers' suggestion } \\
\text { because... }\end{array}$ \\
\hline We acknowledge that..., yet... & We simply do not have such data... \\
\hline We concur with the Reviewer that...; nonetheless... & $\begin{array}{l}\text { Repeating the experiences/analysis would not actually change our } \\
\text { conclusion... }\end{array}$ \\
\hline
\end{tabular}

sary, defending the manuscript, should be written towards the end, right before the resubmission. ${ }^{3}$ Instead letters to each of the reviewers, or a combined point-by-point response to address all reviewers' comments should be the first thing to prepare.

\section{Point-by-point response/Letter to the reviewers}

The point-by-point response is the most important part of the resubmission. ${ }^{3}$ This should always be the first thing to be prepared. It should start by thanking the reviewers for their time spent on the review, and the insightful, constructive comments which are going to improve the manuscript. Then, add a short summary of key changes. The key part would be a specific, dialogue-type list of comments and responses. ${ }^{5}$ For any changes, the authors should indicate the location (page and paragraph numbers) in the new version of manuscript file. For any defenses, try our best to be polite and write professionally (Table 2). ${ }^{3}$

The authors may choose to respond to the easy changes first, which include rewording, adding extra references, an extra paragraph, table, or figure, or an appendix. ${ }^{3}$ All these easy changes should be all addressed accordingly. The authors should always change technical errors as it is the reviewer's job to find these out. Errors in references should always be fixed as skilled reviewers know the history better than newer authors; experts in the field know the correct papers in the correct order. Unfortunately, life is not always that easy. There are often more difficult changes needed, namely modifying the central hypothesis and main algorithm, or even redoing an experiment. ${ }^{1}$ It is particularly essential to change parts which are have been mentioned by multiple reviewers, as repeated comments often stand out to the editor.

\section{Letter to the typesetter}

Very occasionally, if the authors have some specific formatting issue about the manuscript, a letter to the typesetter would be useful. More often this would be prepared at the time the manuscript is accepted and a proof is being prepared.

\section{REVISING THE MANUSCRIPT}

\section{Introduction}

To our surprise, the introduction of a scientific manuscript is often too long. ${ }^{3}$ Unlike review article, we expect a precise and concise introduction. The reviewers often advise to trim the introduction focusing on the study aim and hypothesis. Updated and relevant references are often suggested by the reviewers; the authors essentially should include all these references in the 
revised manuscript.

\section{Methods}

Appropriate and accurate methodology is the foundation of a scientific manuscript warranting publication. ${ }^{3}$ The reviewers can be very critical on this part, such that quite often the changes would involve further data collection, new analysis, and some more experiments. Occasionally, things have been performed appropriate, just that they have not been clearly described in this section. If the further details requested by the reviewers lead to exceeding the word limit, part of this section may be moved to Supplementary Materials.

\section{Results}

Any changes of this part are closely linked with the comments on Method section. Instead of repeating the data which the tables and figures have already presented, reviewers may remove some fine prints. Focusing on the key features of the cohorts, the primary and some important secondary endpoints would be preferred.

\section{Discussion}

This is often the most expanded part after revision. ${ }^{5}$ Many critics, in particulars the limitations raised by the reviewers, should be further addressed in the Discussion. The new findings of the study, especially when they are new or different from current knowledge, should be compared and contrast with existing literature.

\section{References}

With the wide availability of reference manager software, the inconsistency in the format of references is rarely seen nowadays. Instead more often the reviewers (as well as the editors) may ask for some new references to replace to older ones, or adding some relevant studies. Including all suggested new references should be the rule rather than exception.

\section{Tables \& Figures}

As many readers (as well as reviewers) prefer to read the tables and figures rather than the narrative description of results, all tables and figures should be able to stand alone with all abbreviations spelled out in the footnote. Low resolution of figures is another common critic which should be avoided by including high-resolution figures at the first round of submission. ${ }^{3}$

\section{WHY ME? REJECTION AFTER REVISION}

It is frustrating to receive such an email from the editorial office after the authors have spent a lot of time and effort on revising the manuscript:

It is quite often that some of the reviewers wanted to reject the paper at the first round of review, but the handing editor out like to give a chance to revise it. The reviewers may find that unacceptable to have some key methodological issues unresolved in the revised manuscript. Another common weakness would be inconsistent findings between first and second version. ${ }^{3}$ Hence the reviewers may give the following comments at the second review:

As a matter of fact, there is always a proportion of manuscripts not accepted after revision. It happens uncommonly but can be up to $15 \%$ in some high-impact journals.

Hence if we do not want our manuscript belong to part of this proportion, we should try our best to address all reviewers' comments. The authors should always cross-check and proofread the revised manuscript for consistency, grammar and spelling. If there are some key methodological issues that cannot be resolved, the authors should consider either repeat the whole study by the proposed methodology, or to admit this is something the authors cannot resolved in the current study such that future studies are warranted. After all, if the reviewers find the latter response not acceptable, there is always chance to submit the manuscript to another journal.

\section{PERSEVERANCE IS THE KEY TO SUCCESS}

Editors would be satisfied only if the reviewers are satisfied, as they heavily count on reviewers' expertise to make the final decision. The most important tip would be to do whatever the reviewers have suggested if it is possible. From authors' points of view, getting a manuscript accepted after revision can be a tedious process sometimes if there are many challenging comments to be addressed. Yet not to avoid all the troubles to make the changes would be crucial. Looking on the bright side, it is a process to improve the manuscript. Such a positive feedback is often rewarding. Getting the manuscript finally accepted after revisions, be it in the same journal or in other journals means that the effort is finally paid off. So do not give up, be perseverant. I am sure the manuscript will find a good home for publication. Good lucky to everyone who are revising, or going to revise the manuscript.

\section{CONFLICTS OF INTEREST}

Grace Wong has served as the Associate Editor of Alimentary Pharmacology and Therapeutics since February 2017, the Editorial Board Member of 13 journals, the reviewer for 78 journals (including British Medical Journal, Lancet Infectious Disease, Lancet Gastroenterology \& Hepatology, Gastroenterology, Gut, Hepatology, Journal of Hepatology, etc.), and the advisory committee member for Gilead. She has also served as a speaker for Abbott, Abbvie, Bristol-Myers Squibb, Echosens, Furui, Gilead, Janssen, and Roche. 
10 Gut and Liver, Vol. 13, No. 1, January 2019

\section{REFERENCES}

1. Bavdekar SB. Satisfying doubters and critics: dealing with the peer review. J Assoc Physicians India 2016;64:66-69.

2. Thompson SC, Daly J. Help yourself by helping us: responding to reviewers' comments. Aust N Z J Public Health 2012;36:203-204.

3. Provenzale JM. Revising a manuscript: ten principles to guide success for publication. AJR Am J Roentgenol 2010;195:W382W387.

4. Guyatt GH, Brian Haynes R. Preparing reports for publication and responding to reviewers' comments. J Clin Epidemiol 2006;59:900-906.

5. Happell B. Responding to reviewers' comments as part of writing for publication. Nurse Res 2011;18:23-27. 